\title{
Lung anatomy, energy load, and ventilator-induced lung injury
}

\author{
Alessandro Protti ${ }^{1}$, Davide T. Andreis ${ }^{2}$, Marta Milesi ${ }^{2}$, Giacomo E. lapichino ${ }^{2}$, Massimo Monti ${ }^{2}$, Beatrice Comini ${ }^{2}$, \\ Paola Pugni ${ }^{2}$, Valentina Melis ${ }^{2}$, Alessandro Santini ${ }^{1}$, Daniele Dondossola ${ }^{3}$, Stefano Gatti ${ }^{3}$, Luciano Lombardi ${ }^{4}$, \\ Emiliano Votta ${ }^{5}$ Eleonora Carlesso ${ }^{2}$ and Luciano Gattinoni ${ }^{1,2^{*}}$
}

\begin{tabular}{l}
\hline * Correspondence: \\
gattinon@policlinico.mi.it \\
'Dipartimento di Anestesia, \\
Rianimazione ed Emergenza \\
Urgenza, Fondazione IRCCS Ca' \\
Granda-Ospedale Maggiore \\
Policlinico di Milano, Milan, Italy \\
'Dipartimento di Fisiopatologia \\
Medico-Chirurgica e dei Trapianti, \\
Università degli Studi di Milano, Via \\
Francesco Sforza 35, 20122 Milan, \\
Italy \\
Full list of author information is \\
available at the end of the article
\end{tabular}

\begin{abstract}
Background: High tidal volume can cause ventilator-induced lung injury (VILI), but positive end-expiratory pressure (PEEP) is thought to be protective. We aimed to find the volumetric VILI threshold and see whether PEEP is protective per se or indirectly.

Methods: In 76 pigs $(22 \pm 2 \mathrm{~kg})$, we examined the lower and upper limits (30.9-59.7 mL/kg) of inspiratory capacity by computed tomography (CT) scan at $45 \mathrm{cmH}_{2} \mathrm{O}$ pressure. The pigs underwent a 54-h mechanical ventilation with a global strain ((tidal volume (dynamic) + PEEP volume (static))/functional residual capacity) from 0.45 to 5.56 . The dynamic strain ranged from 18 to $100 \%$ of global strain. Twenty-nine pigs were ventilated with end-inspiratory volumes below the lower limit of inspiratory capacity (group "Below"), 38 within (group "Within"), and 9 above (group "Above"). VILI was defined as death and/or increased lung weight.

Results: "Below" pigs did not develop VILI; "Within" pigs developed lung edema, and $52 \%$ died before the end of the experiment. The amount of edema was significantly related to dynamic strain (edema $188-153 \times$ dynamic strain, $R^{2}=0.48, p<0.0001$ ). In the "Above" group, $66 \%$ of the pigs rapidly died but lung weight did not increase significantly. In pigs ventilated with similar tidal volume adding PEEP significantly increased mortality.
\end{abstract}

Conclusions: The threshold for VILI is the lower limit of inspiratory capacity. Below this threshold, VILI does not occur. Within these limits, severe/lethal VILI occurs depending on the dynamic component. Above inspiratory capacity stress at rupture may occur. In healthy lungs, PEEP is protective only if associated with a reduced tidal volume; otherwise, it has no effect or is harmful.

Keywords: Mechanical ventilation, Ventilator-induced lung injury, Lung stress and strain, Inspiratory capacity, Energy load, Experimental animal model

\section{Background}

Various forms of ventilator-induced lung injury (VILI) have been described since the definition of adult respiratory distress syndrome (ARDS) [1]. Barotrauma was the first to be recognized as a form of stress at rupture, leading to pneumothorax, pneumoperitoneum [2], etc. In subsequent years the concept of volutrauma (excessive strain) [3] emerged, and years later, atelectrauma and its inflammatory reaction was recognized, first of all ex-vivo $[4,5]$ then later in clinical settings [6]. Excessive tidal volume is now recognized as the first cause of VILI [7], supporting the concept of volutrauma, while 
limiting airway pressure to $\approx 30 \mathrm{cmH}_{2} \mathrm{O}$ in patients with normal chest wall is used as a surrogate of the maximal tolerable stress (transpulmonary pressure).

The protective effects of positive end-expiratory pressure (PEEP) on VILI were described by Webb and Tierney [8] in their seminal experiments. Although dramatically effective in experimental ARDS, in human ARDS, higher PEEP failed to show clear benefits over lower PEEP [9-11]. Possible benefits were only suggested by meta-analysis in the subgroups of the most severe ARDS patients $[12,13]$. Therefore, while the relation between higher tidal volume and VILI is robust and largely accepted, the protective effects of PEEP are not so widely agreed.

The tidal change in lung volume is associated with a cyclic energy load to the respiratory system; the energy being equal to the pressure applied multiplied by the change in volume $(P \times \mathrm{dV})$, summed along the inspiratory volume-pressure curve. In contrast, PEEP, once applied, does not impose any cyclic energy load as the volume is constant $(\mathrm{dV}=0)$. Therefore, considering both the lung volume distortion and the energy load, we set out to answer the following questions: Is there a threshold of volume distortion/energy load producing VILI? Is the application of PEEP protective per se or is it just an indirect effect, due to the concomitant reduction in tidal volume when it is applied?

Over the years, we have conducted a series of long-term animal experiments in which we tested different tidal volumes (dynamic strain), transpulmonary pressure (dynamic stress), and levels of PEEP (static strain and static stress) [14, 15]. Considering these different experiments together, we concluded that the energy/power load provided a single explanation of the different phenomena. Therefore, we reanalyzed data not previously published from previous experiments and added further experiments to cover a wider range of tidal volumes and PEEP levels. This enabled us to define the interaction between the anatomical limits of lung expansion, as assessed by computed tomography $(\mathrm{CT})$ scan, the inspiratory volumes applied (tidal volume + PEEP volume), and the dynamic and static energy used to induce VILI in healthy animals. Therefore, our aim here is to advance a unifying theory for VILI in the healthy lung, from old and new studies taken together.

\section{Methods}

Ethics, consent, and permissions

This study was approved by the local ethical review board (Ministero della Salute, Direzione Generale della Sanità Animale e dei farmaci veterinari, Rome, Italy); it was conducted according to the Declaration of Helsinki for the use and care of animals and complied with international recommendations [National Research Council (U.S.), Institute for Laboratory Animal Research (U.S.), National Academies Press (U.S.): Guide for the care and use of laboratory animals, 8th ed., Washington, D.C, National Academies Press, 2011].

\section{Experimental procedure}

The study population consisted of 76 anesthetized (propofol and medetomidine iv) and paralyzed (pancuronium bromide iv) healthy pigs $(22 \pm 2 \mathrm{~kg}$ ). Forty-five had already been included in 2 previous studies $[14,15]$ and 31 were specifically added for the present work. At baseline, the pigs underwent a whole-lung CT scan at 0 and 
$45 \mathrm{cmH}_{2} \mathrm{O}$ of constant airway pressure. An additional whole-lung CT scan was done at the clinical PEEP in pigs ventilated with end-expiratory pressure higher than $0 \mathrm{cmH}_{2} \mathrm{O}$. The respiratory system and lung volume-pressure curves were obtained starting from functional residual capacity (FRC) (airway pressure $0 \mathrm{cmH}_{2} \mathrm{O}$ ), in $100-\mathrm{mL}$ steps in 43 of the 76 animals.

We defined global strain as the ratio between the total end-inspiratory volume (tidal volume + PEEP volume) and the FRC, measured with the lung CT scan. We defined dynamic strain as the strain due to tidal volume (tidal volume/FRC) and static strain as the strain due to PEEP (PEEP volume/FRC).

Twenty-nine pigs [14] were ventilated at PEEP $0 \mathrm{cmH}_{2} \mathrm{O}$ with a tidal volume producing a dynamic strain between 0.45 and 3.3, to identify the "lethal strain," which was found to be greater than 2.5. In these pigs, as no PEEP was applied, the global strain was equal to the dynamic strain. Sixteen pigs [15] were treated with a global strain of 2.5 resulting from different proportions of tidal volume (dynamic strain) and volume due to PEEP (static strain) to investigate the protective effect of PEEP. Thirty-one pigs (the ones added in this study, calculating the sample size on the basis of our previous experience) were ventilated with different tidal volumes and PEEP combinations to cover the dynamic/static strain combinations not explored in the two earlier studies.

The global strain applied in the 76 pigs ranged from 0.45 to 5.56 . Dynamic strain ranged from 100 to $18 \%$ of global strain. Figure 1 summarizes the global endinspiratory volume (tidal volume + PEEP volume) and the different dynamic and static proportions. The inspiratory/expiratory time ratio was kept between 1:2 and 1:3, the respiratory rate was set at $15 \mathrm{bpm}$, and the fraction of inspired oxygen was 0.5 . All animals were instrumented with an endotracheal tube, arterial, central venous, pulmonary artery, urinary, and esophageal catheters and kept in anesthesia and paralysis. The experiments were terminated after $54 \mathrm{~h}$ or sooner if animals died.

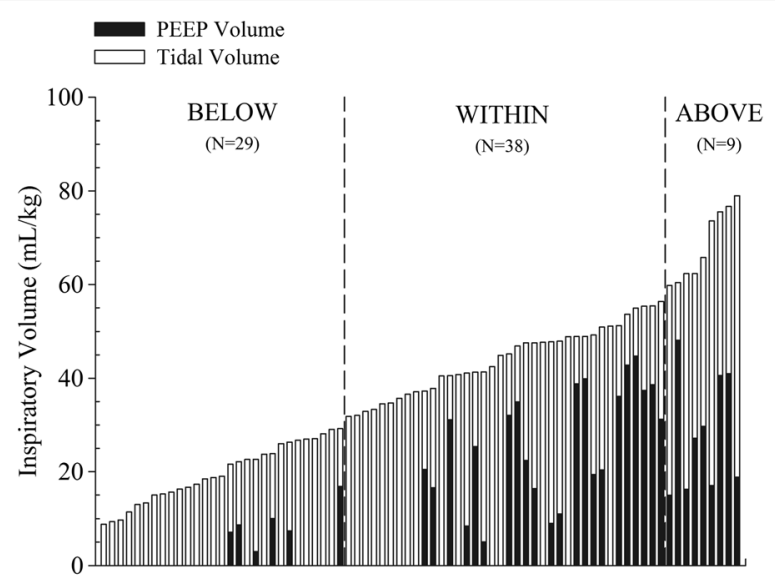

PIG

Fig. 1 Global end-inspiratory volume and the different dynamic and static proportions. The distribution of global end-inspiratory volumes used in this study is shown with the different proportions of dynamic (tidal volume, white bars) and static components (black bars). Pigs were grouped according to end-inspiratory volume lower (BELOW), within (WITHIN), or higher (ABOVE) than normal inspiratory capacity (vertical dashed lines) 


\section{Measurements}

Lung weight, FRC (gas content at $0 \mathrm{cmH}_{2} \mathrm{O}$ PEEP), total lung capacity (TLC, gas content at $45 \mathrm{cmH}_{2} \mathrm{O}$ ), and PEEP volume ((end-expiratory gas content with PEEP)FRC) were measured with quantitative CT scan analysis. The fractions of over, normally, poorly, and not inflated lung tissue were computed using standard CT thresholds (-900, -500, -100 Hounsfield units (HU) [16]). Overall mean pressure-volume curves of the whole respiratory system and of the lung were obtained by averaging the volumes calculated from the individual fittings of the 100-mL steps curves obtained in 43 animals. Volumes were taken at $1 \mathrm{cmH}_{2} \mathrm{O}$ pressure intervals from 0 to $45 \mathrm{cmH}_{2} \mathrm{O}$ of airway pressure and from 0 to $25 \mathrm{cmH}_{2} \mathrm{O}$ of transpulmonary pressure (Fig. 2). The individual curves were fitted with a sigmoidal equation:

$$
V=a+\left[\frac{b}{1+e^{-(P-c) / d}}\right]
$$

The upper inflection point (UIP, the pressures at which the slope rapidly changes) can be defined as UIP $=c+2 d$ and the maximal compliance (at the "most linear" portion of the pressure-volume (PV) curve) is b/4d [17].

\section{Inspiratory capacity}

The inspiratory capacity was measured in each piglet as the difference between TLC and FRC. TLC and FRC were measured with CT scan as the gas content at 45 and $0 \mathrm{cmH}_{2} \mathrm{O}$, respectively. We used the average inspiratory capacity \pm 2 standard deviations as a reference value to which the individual pigs were compared. Airway and transpulmonary pressures corresponding to the upper and lower limits of normal inspiratory capacity were taken from the volume-pressure curves.

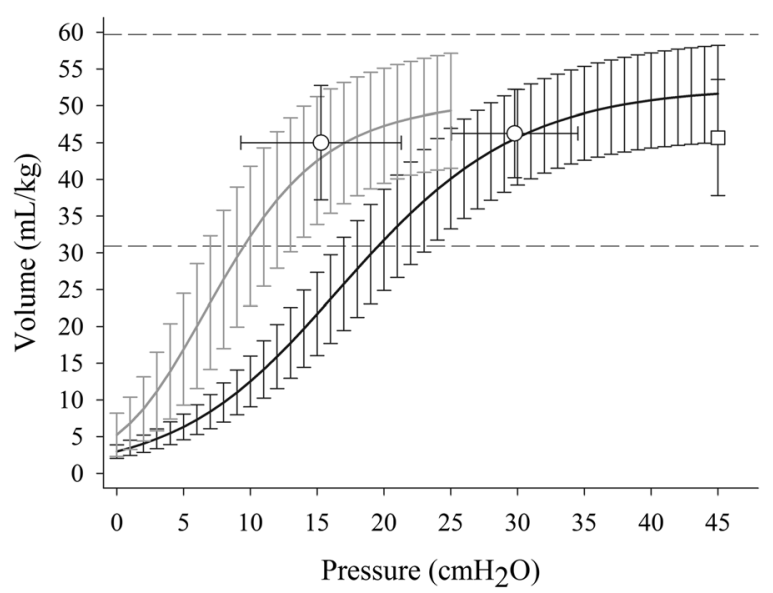

Fig. 2 Respiratory system and lung pressure-volume curve. Mean ( \pm standard deviation) pressure-volume curve of the total respiratory system (black line) and the lung (gray line) obtained by sigmoidal fitting (see text for method). The white dots indicate the upper corner points and the white squares the average inspiratory capacity (TLC-FRC) obtained by $C T$ scan at $45 \mathrm{cmH}_{2} \mathrm{O}$ airway pressure. Horizontal dashed lines indicate the $95 \%$ confidence limits of inspiratory capacity (mean \pm 2 standard deviations) 


\section{Energy load}

The energy load to the respiratory system (Fig. 3) comprises a static component, due to PEEP and PEEP volume (conceptually equivalent to potential energy), and a dynamic cyclic component, due to driving pressure and tidal volume above PEEP (conceptually equivalent to kinetic energy). As a rough simplification:

$$
\begin{aligned}
& \text { Static energy load }=(\text { PEEP } \times \text { PEEP volume }) / 2 \\
& \begin{aligned}
\text { Dynamic energy load } & =(\text { Peak pressure }- \text { PEEP }) \times \mathrm{TV} / 2+(\mathrm{PEEP} \times \mathrm{TV}) \\
& =(\text { PEEP }+ \text { Peak pressure }) \times \mathrm{TV} / 2
\end{aligned}
\end{aligned}
$$

This equation computes the area of the dark gray trapezoid (Fig. 3), where the value of Peak pressure represents the major base, the value of PEEP is the minor base, and the tidal volume represents the height. The area of the trapezoid is the sum of the areas of a "triangle," due to the cyclic tidal breath and to the pressure variation Peak pressure - PEEP only, independent on the "starting value" (PEEP), and of a "rectangle" associated to the lung volume variation starting from a pressure level higher than zero (PEEP).

The energy load computed this way underestimates the energy actually applied cyclically as it does not account for the pressure spent for gas movement, the surface tension forces and tissue resistances to motion. The static energy, after the first application of PEEP, does not imply any further energy load to the respiratory system. During ventilation, the cyclic load to the lung parenchyma is only due to the dynamic energy, although the total energy in the system includes both its static and dynamic components.

\section{Data analysis and outcome measures}

The effects of tidal volume/dynamic strain, airway pressure/stress, and the effects of PEEP on VILI of the single animals were studied using, as a reference, the anatomical limits of the whole population (the upper and lower limits of normal inspiratory capacity). The individual animals were therefore classified as below, within and above groups referring to the whole population studied:

"Below" group-29 pigs globally inflated with a volume of gas smaller than the lower limit of normal inspiratory capacity (ventilation below inspiratory capacity).

"Within" group-38 pigs globally inflated with a volume of gas between the lower and upper limits of normal inspiratory capacity (ventilation at inspiratory capacity).

"Above" group-9 pigs globally inflated with a volume of gas larger than the upper limit of normal inspiratory capacity (ventilation above inspiratory capacity).

VILI was defined as either death or edema. This injury may manifest rapidly as stress at rupture with massive pneumothorax or, more slowly, as progressive edema. Therefore, we considered the "lethal ventilation" and lung edema as outcome measures. The "lethal ventilation" included pigs that died before the scheduled $54 \mathrm{~h}$ of the experiment because of gross pneumothorax or lung edema so severe as to prevent survival. Lung edema compatible with survival at $54 \mathrm{~h}$ is a less severe form of VILI. Lung edema was estimated as the difference between the lung weight directly measured at autopsy at the end of the experiment and lung weight measured by CT scan at baseline.

To clarify better whether PEEP was directly protective on VILI or its protective effect was due to the reduction in tidal volume, we examined the three groups of pigs, as above: animals in which the tidal volume (not the total end-inspiratory volume) was 

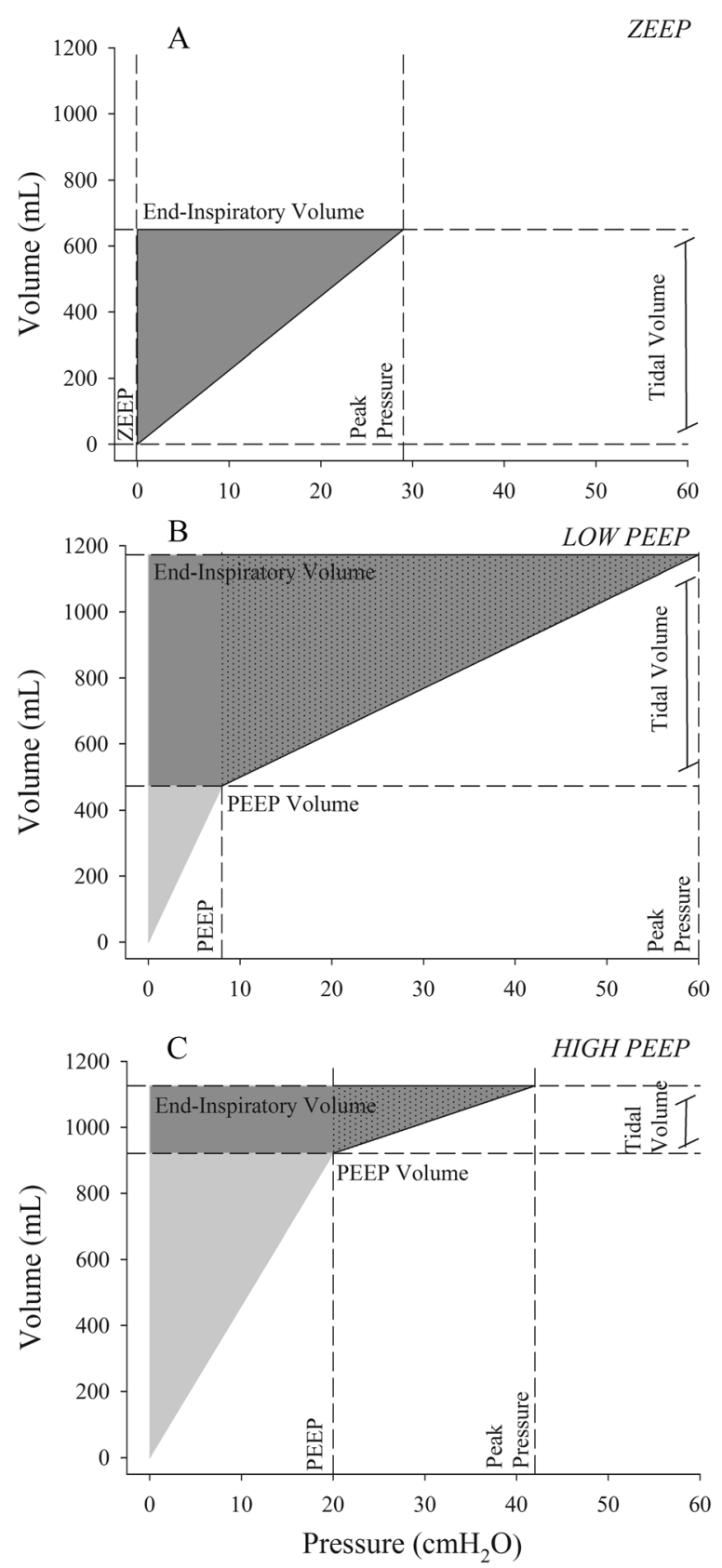

Fig. 3 Energy calculation. Three examples of energy calculation in the following: a a pig ventilated with PEEP 0 $\mathrm{cmH}_{2} \mathrm{O}$, b a pig ventilated with low PEEP $\left(8 \mathrm{cmH}_{2} \mathrm{O}\right)$, and $\mathbf{c}$ a pig ventilated at high PEEP $\left(2 \mathrm{CmH} \mathrm{cm}_{2} \mathrm{O}\right)$. The energy load is composed of a static (when PEEP is higher than $0 \mathrm{cmH}_{2} \mathrm{O}$ ) and a dynamic contribution: global energy load $=$ static energy load + dynamic energy load. Static energy load $=[$ PEEP $\times$ PEEP volume/2] (light gray triangles). Dynamic energy load $=($ Peak pressure $-\mathrm{PEEP}) \times$ TV/2 $+($ PEEP $\times$ TV $)=[($ PEEP + Peak pressure $) \times$ tidal volume / 2] (dark gray triangles (panel a) or trapezoids (panels $\mathbf{b}$ and $\mathbf{c}$ )). The dark gray trapezoids (panel $\mathbf{b}$, c) are composed of a triangle (black dotted area), and a rectangle. The triangle represents the term (Peak pressure - PEEP) $\times$ TV/2, due to cyclic tidal breath; the rectangle represents the term $(P E E P \times T V$ ) due to the ventilation (volume change) starting from a pressure level higher than zero (PEEP). Vertical dashed lines indicate PEEP and peak pressures; horizontal dashed lines PEEP volume and end-inspiratory volume (tidal volume is the difference between the two) 
below, within, or higher than the boundaries of normal inspiratory capacity. As only one pig had a tidal volume exceeding the upper limit, we analyzed only two groups, one in which the tidal volume (dynamic strain) was below the lower limit of inspiratory capacity (47 pigs) and one (29 pigs) in which the tidal volume was above the lower limit.

\section{Statistical analysis}

Results are reported as mean \pm standard deviation. Continuous data were analyzed with Student's $t$ test, Wilcoxon's signed rank test, as appropriate, and two-way analysis of variance (ANOVA) (on ranks when appropriate). Associations between variables were analyzed with linear regression. Categorical data were compared with the chi-square test. A two-tailed $p<0.05$ indicated statistical significance (Sigma Plot 11, Jandel Scientific Software; San Jose, CA).

\section{Results}

The baseline characteristics of the respiratory system of these 76 healthy pigs, measured in prone position during anesthesia and muscle relaxation, are summarized in Table 1. The lower and upper limits of normal inspiratory capacity were 30.9 and $59.7 \mathrm{~mL} / \mathrm{kg}$ body weight, i.e., two standard deviations from the mean. The upper and lower limits of airway pressure were 20.3 and $39.3 \mathrm{cmH}_{2} \mathrm{O}$, i.e., also two standard deviations from the mean.

Figure 4 shows the outcome of the pigs ventilated with end-inspiratory volumes (tidal volume plus PEEP volume) below, within, and above the limits of normal inspiratory capacity. The upper panels present the inspiratory volume (A) and associated strain (B), and the lower panels show the airway (C) and transpulmonary pressures (stress, D). Mechanical ventilation was lethal (at the rate of $15 \mathrm{bpm}$ ) only when end-inspiratory

Table 1 Baseline lung characteristics

\begin{tabular}{|c|c|}
\hline Lung weight (g) & $321 \pm 40$ \\
\hline Functional residual capacity (FRC) (mL) & $388 \pm 93$ \\
\hline Inspiratory capacity (mL) & $968 \pm 165$ \\
\hline Inspiratory capacity (mL/kg) & $45.3 \pm 7.2$ \\
\hline Total lung capacity (mL) & $1357 \pm 225$ \\
\hline Total lung capacity (mL/kg) & $63.4 \pm 9.9$ \\
\hline Upper inflection point volume (mL) & $991 \pm 147$ \\
\hline Upper inflection point airway pressure $\left(\mathrm{cmH}_{2} \mathrm{O}\right)$ & $29.8 \pm 4.7$ \\
\hline Maximal total respiratory system elastance $\left(\mathrm{cmH}_{2} \mathrm{O} / \mathrm{L}\right)$ & $22.4 \pm 5.0$ \\
\hline Specific lung elastance $\left(\mathrm{cmH}_{2} \mathrm{O}\right)$ & $6.72 \pm 3.07$ \\
\hline Non-aerated tissue at FRC (g (\%)) & $17 \pm 13(5 \% \pm 3)$ \\
\hline Poorly aerated tissue at FRC (g (\%)) & $117 \pm 61(36 \% \pm 17)$ \\
\hline Well-aerated tissue at FRC (g (\%)) & $186 \pm 52(59 \% \pm 17)$ \\
\hline Over-aerated tissue at FRC (g (\%)) & $0.02 \pm 0.04(0 \% \pm 0)$ \\
\hline
\end{tabular}




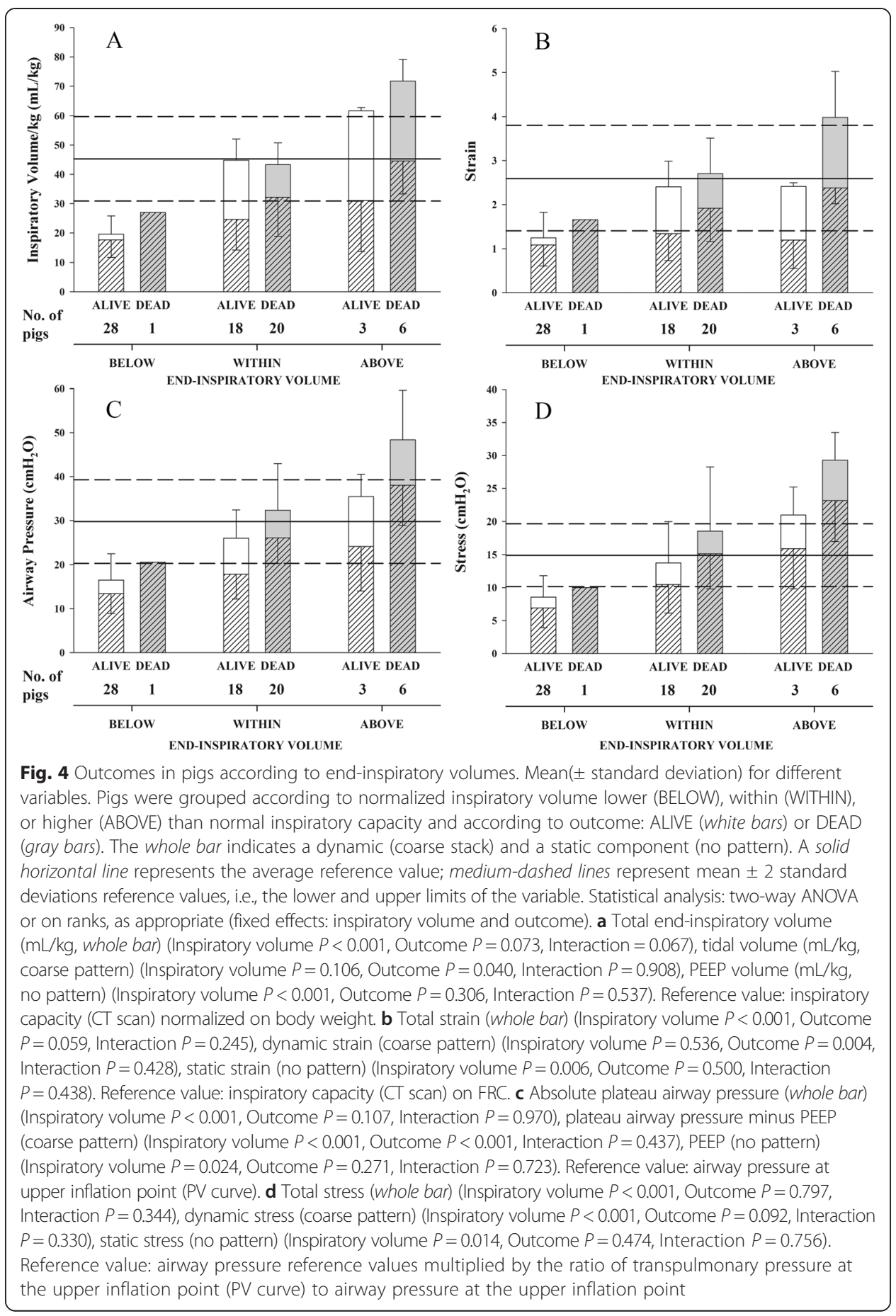

volumes were within or above the limits of normal inspiratory capacity ("Within" and "Above" groups). The contribution of the tidal volume and PEEP volume to the total endinspiratory volume seems to play a significant role too. Panels a and b of Fig. 4 show that out of the 38 animals which had similar total end-inspiratory volumes, within the limits of inspiratory capacity, the 20 that finally died had significantly larger tidal volumes (dynamic strain) than the 18 that survived $(32.2 \pm 13.3 \mathrm{~mL} / \mathrm{kg}$ and $24.7 \pm 10.4 \mathrm{~mL} / \mathrm{kg}, P=0.03)$. The 
PEEP volume tended to be lower, though not significantly so, in non-survivors than survivors $(11.1 \pm 16.6 \mathrm{~mL} / \mathrm{kg}$ and $20.2 \pm 14.7 \mathrm{~mL} / \mathrm{kg}, P=0.06)$.

Similarly, the 20 pigs ventilated within the limits of inspiratory capacity which finally died had significantly higher dynamic and global energy loads $(2.02 \pm 1.00$ and $2.28 \pm 0.86 \mathrm{~J})$ than the 18 pigs that survived $(1.20 \pm 0.54 \mathrm{~J}(P=0.004)$ and $1.47 \pm 0.45 \mathrm{~J}(P<0.001)$ (Fig. 5). The static component, in contrast, was not significantly different $(0.26 \pm 0.46$ and $0.27 \pm 0.32 \mathrm{~J}, P=0.10)$.

As VILI may not be severe enough to be lethal, but sufficient to cause significant lung edema, Fig. 6 illustrates the relationship between the dynamic strain and lung weight changes in the three groups of pigs, independently of survival. In the pigs with endinspiratory volume above the limits of normal inspiratory capacity ("Above" group), we did not see any significant relationship between dynamic strain and edema. However, this group had a significant relationship between edema formation and time to death, indicating that "time is necessary" for edema to develop (edema $=-144.1+8.5 \times$ time to death, $R^{2}=0.54, P=0.02$ ).

In the pigs with global strain below the lower limit of normal inspiratory capacity ("Below" group), there was no significant increase in lung weight and all, but one survived the whole experiment. In contrast, we found a significant relationship between lung weight increase and dynamic strain applied in the 38 pigs ventilated within the limits of inspiratory capacity ("Within" group). However, lung weight increased without exception only at a dynamic strain higher than 2 .

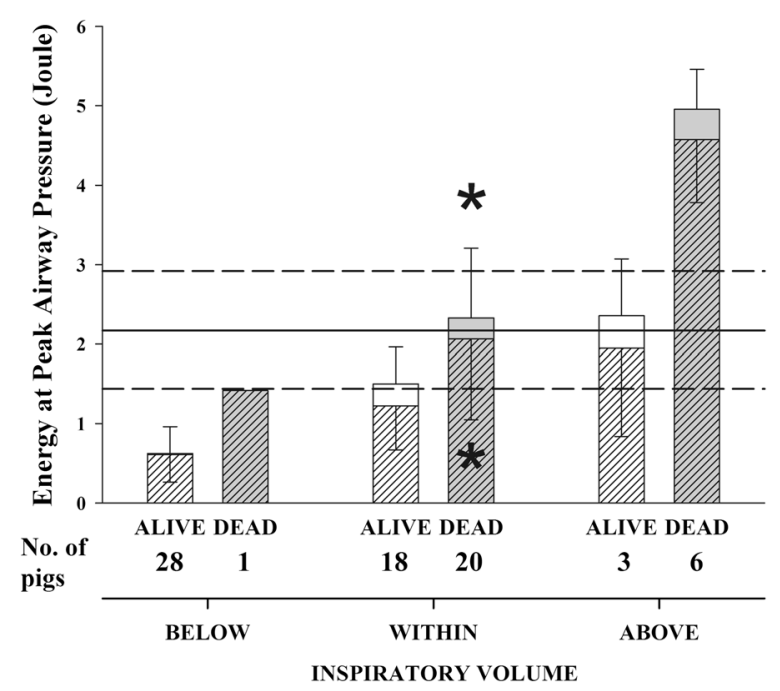

Fig. 5 Outcomes of pigs and energy at peak airway pressure. Mean ( \pm standard deviation) energy at peak airway pressure, expressed as joule. Pigs were grouped according to normalized inspiratory volume lower (BELOW), within (WITHIN) or higher (ABOVE) than normal inspiratory capacity. Pigs were also divided according to outcome: ALIVE (white bars) or DEAD (gray bars). The whole bar is composed of a dynamic component (coarse stack) and a static component (the stack with no pattern). A solid horizontal line indicates the average reference value of energy at $45 \mathrm{CmH}_{2} \mathrm{O}$ airway pressure, medium-dashed lines represent mean \pm 2 standard deviation reference values, i.e. the lower and the upper limits of the variable. Statistical analysis: two-way ANOVA on ranks (fixed effects: Inspiratory volume and Outcome). Total energy at peak airway pressure (entire bar) (Inspiratory volume $P<0.001$, Outcome $P<0.001$, Interaction $=0.804$ ), dynamic energy at peak airway pressure (coarse pattern) (Inspiratory volume $P=0.005$, Outcome $P<0.001$, Interaction $=0.597$ ), static energy at peak airway pressure (no pattern) (Inspiratory volume $P=0.002$, Outcome $P=0.333$, Interaction $=0.618$ ). ${ }^{*} P<0.05$ between dead and alive pigs in the WITHIN group (see text for description) 


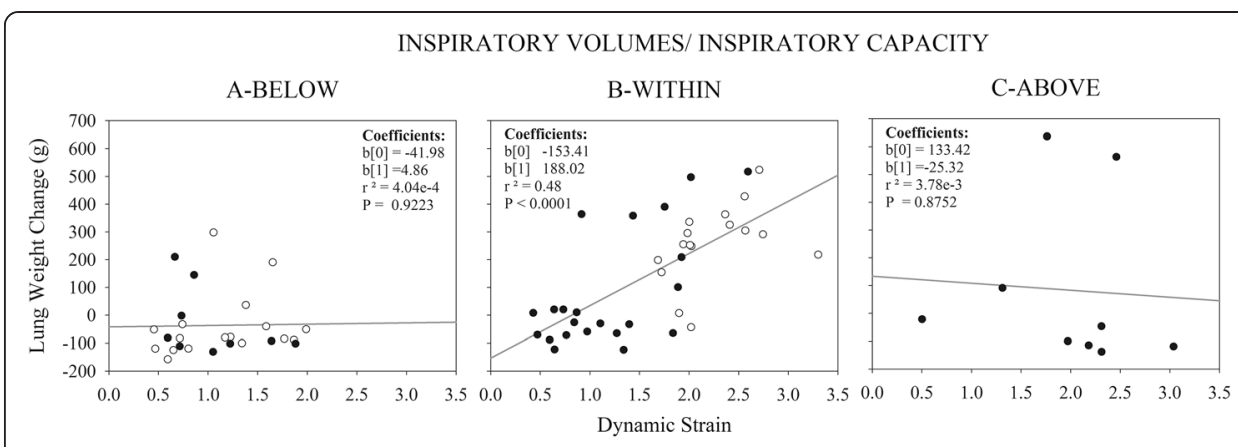

Fig. 6 Dynamic strain and increase in lung weight. Relationships between the dynamic strain and the lung weight increase. Pigs were grouped according to normalized inspiratory volume lower (BELOW), within (WITHIN) or higher (ABOVE) than normal inspiratory capacity. They were also divided according to PEEP $\left(0 \mathrm{cmH}_{2} \mathrm{O}\right.$, white dots; $>0 \mathrm{cmH}_{2} \mathrm{O}$, black dots)

The effects of ventilating these pigs with inspiratory volumes below, within, or above the lung capacity on gas exchange or respiratory mechanics are summarized in Table 2. In the "Below" pigs, although lung weight did not increase, there was a slight but significant deterioration of gas exchange, with a bigger increase in lung elastance. In the "Within" group, the significant increase of lung weight at the end of the experiments was associated with sharp deterioration of gas exchange and marked impairment of lung mechanics. Interestingly, in the "Above" pigs, we found no significant deterioration of gas exchange or lung mechanics at the end of the experiments. Lung elastance, in fact, although abnormally elevated at baseline (because of the extreme ventilator settings) did not get significantly worse during the experiments.

The hemodynamic consequences of ventilating at different end-inspiratory volumes are summarized in Table 3. In the pigs ventilated below inspiratory capacity ("Below" group), the only significant findings at the end of the experiments were small decreases in heart rate and central venous oxygen saturation. In contrast, in the group ventilated with end-inspiratory volumes within inspiratory capacity ("Within" group) at the end of the experiments, pulmonary artery pressure and heart rate were both significantly increased, with significant drops in mean arterial pressure and central venous oxygen saturation. Finally, there were no significant changes in the group ventilated above the upper limits of inspiratory capacity (“Above” group).

Table 4 groups the pigs according to their tidal volume (not end-inspiratory volume). In the first group, the median tidal volume $(16.3[12.2-22.6] \mathrm{mL} / \mathrm{kg})$ was below the lower limit of the normal inspiratory capacity $(30.9 \mathrm{~mL} / \mathrm{kg})$, while in the second group, the median tidal volume (36.6 [34.7-44.7] $\mathrm{mL} / \mathrm{kg}$ ) exceeded the lower limit. Animals in the first group that survived had significantly lower PEEP than the animals that died.

\section{Discussion}

In this study, we considered VILI in the framework of lung anatomical constraints and physical forces. To do so, we had to rely on variables such as strain, stress, and mechanical energy instead of tidal volume/kilogram ideal body weight and airway pressures (plateau and PEEP). Strain measures the actual distortion of the lung: for the same tidal volume/kilogram, the strain may be completely different depending on the size of the "baby lung" $[18,19]$. Likewise, the same airway pressure may result in widely 
Table 2 Gas exchange and respiratory mechanics

\begin{tabular}{|c|c|c|c|c|c|c|c|c|c|}
\hline \multirow[b]{4}{*}{ No. } & \multicolumn{9}{|c|}{ End-inspiratory volumes/inspiratory capacity } \\
\hline & \multicolumn{3}{|l|}{ Below } & \multicolumn{3}{|l|}{ Within } & \multicolumn{3}{|l|}{ Above } \\
\hline & First & Last & $P$ & First & Last & $P$ & First & Last & $P$ \\
\hline & 29 & & & 38 & & & 9 & & \\
\hline Lung weight (g) & 308 [287-350] & $253[220-275]$ & 0.057 & 317 [294-349] & $483[301-655]$ & $<0.001$ & $325[287-340]$ & $242[220-430]$ & 0.820 \\
\hline $\mathrm{PaCO}_{2}(\mathrm{mmHg})$ & $38.0[34.0-43.0]$ & $30.0[26.0-40.0]$ & 0.005 & $39.5[36.0-43.0]$ & $46.5[39.0-56.0]$ & 0.002 & $35.8[34-41.7]$ & $40.8[35.0-48.8]$ & 0.056 \\
\hline $\mathrm{PaO}_{2}(\mathrm{mmHg})$ & $234.5 \pm 46.0$ & $202.6 \pm 58.4$ & 0.020 & $229.0 \pm 40.3$ & $133.3 \pm 75.1$ & $<0.001$ & $243.7 \pm 27.8$ & $178.8 \pm 83.9$ & 0.061 \\
\hline Ers $\left(\mathrm{cmH}_{2} \mathrm{O} / \mathrm{L}\right.$ & $32.9[29.8-38.8]$ & $43.7[35.6-53.2]$ & $<0.001$ & $33.3[29.4-45.3]$ & $51.0[42.8-61.6]$ & 0.005 & $42.3[34.9-47.4]$ & $52.9[41.8-56.8]$ & 0.292 \\
\hline $\mathrm{EcW}\left(\mathrm{cmH}_{2} \mathrm{O} / \mathrm{L}\right)$ & 17.9 [14.5-20.2] & 15.9 [14.8-19.8] & 0.270 & 16.4 [13.5-19.0] & 15.9 [14.3-19.4] & 1.00 & 14.2 [13.0-19.3] & $14.1[13.7-17.8]$ & 0.808 \\
\hline $\mathrm{El}\left(\mathrm{cmH}_{2} \mathrm{O} / \mathrm{L}\right)$ & 15.4 [12.3-22.3] & 27.4 [20.2-39.3] & $<0.001$ & 19.2 [14.0-30.9] & 33.0 [25.9-43.5] & 0.018 & 28.1 [27.6-29.8] & $42.7[35.6-44.6]$ & 0.159 \\
\hline IL-6 (pg/mL) & $10.0[10.0-54.0]$ & $10.0[10.0-80.0]$ & 1.00 & 16.5 [10.0-39.0] & 185.5 [12.0-449.0] & $<0.001$ & $10.4[5.3-14.3]$ & $14.3[5.2-694.0]$ & 0.500 \\
\hline
\end{tabular}

Mean \pm standard deviation or median (interquartile range) of gas exchange and respiratory mechanics at the beginning (FIRST) and end (LAST) of the experiments. Pigs were grouped according to end-inspiratory volume as lower (BELOW), within (WITHIN), or higher (ABOVE) than normal inspiratory capacity. P refers to paired $t$ test or Wilcoxon's Signed Rank Test, as appropriate. Lung weight (available data, 26 below,

38 within, 9 above)
$\mathrm{PaCO}_{2}$ indicates partial pressure of carbon dioxide (29 below, 38 within, 6 above), $\mathrm{PaO}_{2}$ indicates partial pressure of oxygen (29 below, 38 within, 6 above), Ers indicates respiratory system elastance (26 below,

37 within, 6 above), Ecw indicates chest wall elastance ( 24 below, 31 within, 5 above), El indicates lung elastance ( 24 below, 31 within, 5 above), IL- 6 indicates serum interleukin 6 (17 below, 28 within, 3 above) 
Table 3 Hemodynamic variables

\begin{tabular}{|c|c|c|c|c|c|c|c|c|c|}
\hline \multirow[b]{4}{*}{ No. } & \multicolumn{9}{|c|}{ End-inspiratory volumes/inspiratory capacity } \\
\hline & \multicolumn{3}{|l|}{ Below } & \multicolumn{3}{|l|}{ Within } & \multicolumn{3}{|l|}{ Above } \\
\hline & First & Last & $P$ & First & Last & $P$ & First & Last & $P$ \\
\hline & 29 & & & 38 & & & 9 & & \\
\hline $\mathrm{CO}(\mathrm{L})$ & $2.1[1.9-2.8]$ & $2.0[1.6-2.4]$ & 0.277 & $2.00[1.70-2.20]$ & $2.10[1.50-2.80]$ & 0.569 & $2.40[2.35-2.45]$ & $2.05[1.80-2.75]$ & 0.776 \\
\hline Mean arterial blood pressure $(\mathrm{mmHg})$ & $86.4 \pm 16.1$ & $77.5 \pm 16.3$ & 0.084 & $78.5 \pm 12.3$ & $57.3 \pm 16.4$ & $<0.001$ & $74.7 \pm 12.2$ & $77.0 \pm 24.7$ & 0.823 \\
\hline Mean pulmonary artery pressure $(\mathrm{mmHg})$ & $15.8 \pm 5.4$ & $17.8 \pm 6.3$ & 0.157 & $19.8 \pm 7.8$ & $25.0 \pm 9.8$ & 0.005 & $23.9 \pm 3.4$ & $23.7 \pm 4.09$ & 0.911 \\
\hline HR (bpm) & $97.4 \pm 21.3$ & $83.8 \pm 26.1$ & 0.026 & $108.9 \pm 34.6$ & $132.6 \pm 49.0$ & 0.021 & $121.8 \pm 31.0$ & $127.2 \pm 47.1$ & 0.846 \\
\hline $\mathrm{SvO}_{2}$ & $65.2 \pm 8.4$ & $59.8 \pm 13.5$ & 0.036 & $58.0 \pm 11.9$ & $48.0 \pm 18.7$ & 0.013 & $57.3 \pm 11.2$ & $52.7 \pm 8.9$ & 0.372 \\
\hline
\end{tabular}

Mean \pm standard deviations or median (interquartile range) of hemodynamic variables at the beginning (FIRST) and end (LAST) of the experiments. Pigs were grouped according to end-inspiratory volume as lower

(BELOW), within (WITHIN), or higher (ABOVE) than normal inspiratory capacity. P refers to paired $t$ test or Wilcoxon's Signed Rank Test, as appropriate. CO indicates cardiac output (available data, 22 below, 26 within, 4 above); mean arterial blood pressure (29 below, 37 within, 6 above); mean pulmonary artery pressure (26 below, 28 within, 5 above)

$H R$ heart rate (27 below, 34 within, 5 above), $\mathrm{SvO}_{2}$ venous oxygen saturation ( 29 below, 33 within, 6 above) 
Table 4 Respiratory mechanics in pigs grouped according to tidal volume

\begin{tabular}{|c|c|c|c|c|c|c|}
\hline \multirow[b]{3}{*}{ No. } & \multicolumn{3}{|c|}{$\begin{array}{l}\text { Tidal volume below the lower limit of } \\
\text { normal inspiratory capacity }\end{array}$} & \multicolumn{3}{|c|}{$\begin{array}{l}\text { Tidal volume above the lower limit of } \\
\text { normal inspiratory capacity }\end{array}$} \\
\hline & Alive & Dead & $P$ & Alive & Dead & $P$ \\
\hline & 40 & 7 & & 9 & 20 & \\
\hline Tidal volume (mL/kg) & $16.0[13.0-23.5]$ & $16.7[10.0-21.1]$ & 0.591 & $34.7[32.5-38.6]$ & $37.0[35.6-46.3]$ & 0.045 \\
\hline PEEP $\left(\mathrm{cmH}_{2} \mathrm{O}\right)$ & $5[0-10]$ & 20 [6-26] & 0.010 & $4[0-5]$ & $0[0-6]$ & 0.698 \\
\hline PEEP/ZEEP & $24 / 16$ & $6 / 1$ & 0.165 & $5 / 4$ & $8 / 12$ & 0.436 \\
\hline Inspiratory volume (mL/kg) & $23.8[16.5-43.3]$ & $48.9[37.8-55.3]$ & 0.009 & $41.1[34.7-47.8]$ & $46.3[36.8-62.8]$ & 0.334 \\
\hline Global strain & $1.74[0.90-2.21]$ & $2.82[2.44-4.18]$ & $<0.001$ & $2.34[2.02-2.44]$ & $2.64[2.21-3.17]$ & 0.085 \\
\hline Dynamic strain & $0.87[0.65-1.34]$ & $0.97[0.73-1.40]$ & 0.630 & $1.93[1.84-2.02]$ & $2.34[1.98-2.58]$ & 0.005 \\
\hline Static strain & $0.00[0.00-1.15]$ & $2.18[1.11-2.97]$ & 0.005 & $0.48[0.00-0.63]$ & $0.00[0.00-0.72]$ & 0.698 \\
\hline $\mathrm{FRC}(\mathrm{mL})$ & $397 \pm 102$ & $361 \pm 73$ & 0.370 & $387 \pm 78$ & $382 \pm 91$ & 0.880 \\
\hline
\end{tabular}

Mean \pm standard deviations or median (interquartile range) or occurrences of respiratory mechanics variables in pigs grouped according to their tidal volume (not end-inspiratory volume) in relation to normal inspiratory capacity (below or above the lower limit). Pigs were then grouped according to outcome. $P$ refers to paired $t$ test or Wilcoxon's Signed Rank Test, as appropriate, for continuous variables and the chi-square test for categorical variables

$P E E P$ indicates positive end-expiratory pressure, ZEEP indicates zero end-expiratory pressure, $F R C$ indicates functional residual capacity

differing transpulmonary pressures (stress), depending on the relationship between lung and chest wall elastances [20]. The initial trigger of stress and strain, however, is the force applied to the extracellular matrix times its displacement, which equals the product of pressure times delta-volume $(P \times \mathrm{dV})$. The cyclic energy loads applied at a given frequency (power) trigger the VILI, which may be seen in this context as a sort of "fatigue" of the extracellular matrix, similar to material "fatigue" [21-24]. We believe that the energy/power concept, which encompasses stress, strain, frequency, and flow rate, explains the different effects of tidal volume (dynamic), PEEP (static), and the physical thresholds conditioning the appearance of VILI.

\section{Inspiratory capacity}

Referring to inspiratory capacity, we used a range derived from the whole population instead of a single value to account for physiological variability (inspiratory capacities were normally distributed in our population). The resulting distribution of inspiratory capacity is of the same order of magnitude as in humans $(\approx 1 / 3$ of the mean) [25]. The ratio of inspiratory capacity (TLC-FRC) to resting lung volume (FRC) in these pigs was $2.6 \pm 0.6$, similar to mice $(\approx 2-2.3$, TLC $\approx 1-1.5 \mathrm{~mL}$ FRC $\approx 0.3-0.5 \mathrm{~mL})$ [26-28], rats $(\approx 2-3$, $\mathrm{TLC} \approx 10 \mathrm{~mL}, \mathrm{FRC} \approx 2.5-3 \mathrm{~mL})[28,29]$, and normal humans $(\approx 2.2, \mathrm{TLC} \approx 7000 \mathrm{~mL}$, FRC $\approx 2200 \mathrm{~mL})[28,30]$. Therefore, in the species most commonly used to study VILI, the limits of physical expansion of the lung are 2-3 times the FRC, i.e., strain between 2 and 3 .

While the strain to reach inspiratory capacity is similar within the species, the associated stress (equal to the transpulmonary pressure) differs widely, due to differences in specific elastance. As an example, the specific elastance (transpulmonary pressure necessary to double the FRC) is approximately $4 \mathrm{cmH}_{2} \mathrm{O}$ in rats [31], $6 \mathrm{cmH}_{2} \mathrm{O}$ in pigs [14], and $12 \mathrm{cmH}_{2} \mathrm{O}$ in humans [20]. Therefore, the stress associated with inspiratory capacity may vary widely within a species, and this must be kept in mind when experimental research is translated to the human being. 


\section{Volume and pressure thresholds for ventilator-induced lung injury}

Our findings indicate that the volumetric threshold for VILI coincides with the anatomical limits of lung expansion. In the pigs ventilated with end-inspiratory volumes below the lower limits of inspiratory capacity, we could not find any real increase of lung weight, suggesting there was no VILI. The slight deterioration of gas exchange and the increased lung elastance in this group were very likely due to dependent atelectasis after $54 \mathrm{~h}$ of anesthesia and paralysis [32-34]. The "stress at rupture" appeared in the "Above" group where the end-inspiratory volume exceeded the upper limit of inspiratory capacity, probably overcoming the collagen's ultimate strain [35]. In the "Within" group, at lower stress and strain, the appearance of edema was proportional to tidal volume (Fig. 6). Strain at the lower limit of inspiratory capacity in our experiments was 1.4, and the associated stress averaged $10.2 \mathrm{cmH}_{2} \mathrm{O}$, corresponding to an airway pressure of $20.3 \mathrm{cmH}_{2} \mathrm{O}$. Below these values, no VILI occurred ("Below" group).

While the pressometric values cannot be translated as such to the human being due to differences in specific elastance, the strain threshold we found $(\approx 2.6)$ was similar to the harmful lethal strain found in mice, rats, rabbits, pigs, and sheep [29].

\section{Dynamic versus static strain}

How the volumetric/pressometric thresholds are reached seems important in relation to the appearance and severity of VILI. Webb and Tierney [8], in their seminal experiments on rats ventilated at $45 \mathrm{cmH}_{2} \mathrm{O}$ airway pressure for nearly $1 \mathrm{~h}$, found huge damage when global strain was $100 \%$ dynamic (tidal volume) but only minimal damage when the same global strain was $66 \%$ dynamic (tidal volume) and $33 \%$ static (PEEP). The same observations were reported by Dreyfuss and coworkers [3]. We recently found that global strain of 2.5 in pigs was lethal if $100 \%$ dynamic (tidal volume) but safe if $25 \%$ dynamic and $75 \%$ static [15]. Similarly, the dynamic strain induced damage in cell cultures while the same strain in static conditions did not [36]. The bulk of data so far, therefore, leads to the common belief that dynamic strain (tidal volume) is harmful while static strain (PEEP) is "protective".

It is convenient, in our opinion, to interpret these results taking into account the energy load associated with dynamic and static strain. The energy load is the integral of $P \times \mathrm{dV}$ along the PV curve. If an "excess" of energy is loaded onto the system, we can expect the unrecovered energy to be sufficient to break the molecular bonds of the polymers of the extracellular matrix [37-39], to detach endothelial [21] and epithelial cells [40] from the basement membrane, and to fracture the capillary walls [41]. Alteration of the extracellular matrix with the appearance of polymers with lower molecular weight, combined with capillary micro-fractures, may activate the inflammatory reaction [42] and micro-hemorrhage, leading to the extracellular edema typical of VILI.

The behavior of PEEP is more complex. PEEP provides increased continuous tension to the extracellular matrix which accumulates energy equal to $(\mathrm{PEEP} \times \mathrm{PEEP}$ volume $) / 2$. Further energy is added when tidal volume (dynamic cyclic energy) is superimposed on the PEEP to reach a given end-inspiratory volume. Therefore, if the end-inspiratory volume is the same, with or without PEEP, the energy is lower in the presence of PEEP than without it (Fig.3), as in our group of "Within" animals. In contrast, if the same tidal 
volume is provided with or without PEEP, the energy with PEEP will be higher and potentially harmful, as presumably occurred in our "Above" group (Table 4). Therefore, considering the energy associated with a given ventilatory mode, it is clear that the independent variable for VILI is dynamic strain (tidal volume), while PEEP is "protective" as far as it is associated with a lower tidal volume, as in the "Within" group. Otherwise, it has no effect, as in the "Below" group, or is even harmful, as in the "Above" group.

Finally, when considering energy, we cannot ignore the respiratory rate. All our experiments were done at $15 \mathrm{bpm}$, but it is always possible that at a lower rate, there would be less severe damage-or none at all-for the same exposure time.

\section{Translation to a clinical scenario}

Taken with the appropriate caution, our findings may be of some interest when approaching mechanical ventilation in human ARDS. This syndrome involves reduced FRC - the baby lung $[18,19]$. As the specific elastance of the baby lung is usually normal [20], we may expect the volumetric threshold, if similar to pigs, to be $\approx 2.6 \pm 0.6$ times higher. As an example, in a 70-kg man with severe ARDS, if the baby lung is around $300 \mathrm{~mL}$, ignoring for simplicity's sake $10-15 \%$ of recruitability, the inspiratory capacity would be $780 \mathrm{~mL}$. At $12 \mathrm{~mL} / \mathrm{kg}$ body weight, the tidal volume would be $840 \mathrm{~mL}$, within the range of inspiratory capacity. If we refer to the lower limits of inspiratory capacity $((2.6-2 \times 0.6 \times 300=420 \mathrm{~mL})$, even the $6 \mathrm{~mL} / \mathrm{kg}$ ventilation would be close to the volumetric threshold. To translate the pressometric threshold of pigs to humans, the pressure observed in pigs at inspiratory capacity should be approximately multiplied by 2 , to take account of the difference in specific elastance.

In addition, we must remember the "inhomogeneity" factor. We estimated that the uneven distribution of volumes and pressure could induce local stress/strain about double that computed for the whole lung [43]. Therefore, in an ARDS patient, knowing the volumes and transpulmonary pressure, and taking account of the inhomogeneity factor, we can forecast whether in a given patient low tidal volume ventilation will still be safe or alternative forms of respiratory assistance, such as an artificial lung, should be employed.

The driving pressure has been recently advocated as the variable most related to VILI [44]. The driving pressure, however, should be considered in relation with the chest wall elastance, the lung size, homogeneity, and gas flow rate. Depending on the combination of these variables, the same driving pressure may be "lethal or innocent". In summary, our study confirms that a single variable cannot explain the complexity of VILI. The concept of energy and power, encompassing several different variables, may reconciliate some of the contradictions present in the literature.

Similar concepts may be applied when considering the harm of high tidal volume ventilation during anesthesia or ventilating ICU patients with uninjured lungs. The primary difference between a normal lung and the ARDS lung is that, for a given tidal volume, the stress and strain are greater in ARDS [20] due to the inhomogeneities of the lung parenchyma [43] and the size of the "baby lung". However, also the "normal" lung in anesthesia or the uninjured lung during mechanical ventilation [45] may present inhomogeneity with mal-distributed stress due to comorbidities or aging. Current data from large randomized trials and meta-analyses on the effects of 
mechanical ventilation on pulmonary complications during anesthesia show that the number of complications increases with tidal volume and driving pressure, with increasing tidal volume at the same PEEP [46-48], increasing tidal volume at low PEEP [46, 48-50] and increasing PEEP at constant tidal volume [51]. All these results are in line with the model presented in this paper.

\section{Limitations}

We recognize that the largest threat to the interpretation of our data hinge on the reliance of data collected in previous studies. Therefore, biases arising from the use of historical data may be present. However, the experimental animals were all of the same breed, had similar weight, were coming from the same farm, and experiments were conducted by the same people in the same experimental setting. In addition, we believe that a prior data publication does not compromise the novelty of a study if it goes beyond a descriptive analysis of the data and report new scientific findings [52].

\section{Conclusions}

We found that the threshold of VILI in the healthy lung is the region defining the inspiratory lung capacity, i.e., the anatomical limits of lung expansion. When the inflated volume is below the threshold, VILI does not occur, and if it is within the limits, it appears as a main function of its dynamic component. If it exceeds the total lung capacity, stress at rupture occurs. A unifying explanation is that the trigger for VILI is an excessive energy/power load, which encompasses pressures, volume and-though not tested in the present study-respiratory rate and flow. PEEP, not associated with energy input, appears to prevent VILI if the tidal volume is lower. Otherwise, PEEP may be harmful as it just boosts inflation closer to the total lung capacity.

\footnotetext{
Abbreviations

ANOVA: analysis of variance; ARDS: acute respiratory distress syndrome; CT: computed tomography; FRC: functional residual capacity; HU: Hounsfield units; PEEP: positive end-expiratory pressure; PV: pressure-volume; $P \times d V$ : pressure times volume change; SD: standard deviation; TLC: total lung capacity; TV: tidal volume; UIP: upper inflection point; VILI: ventilator-induced lung injury.
}

Competing interests

The authors declare that they have no competing interests.

\section{Authors' contributions}

AP conceived the study, participated in its design and coordination, interpreted the data, and drafted the manuscript. DTA participated in the study conception and design and data acquisition. MMilesi, GEI, MMonti, BC, PP, and VM participated in data acquisition, analysis (CT scan image segmentation), and interpretation. AS participated in data acquisition and interpretation and critically reviewed the manuscript. DD and SG participated in data acquisition (surgical preparation) and critically reviewed the manuscript. LL participated in data acquisition (CT scan analysis) and critically reviewed the manuscript. EV participated in the study design, interpreted the data, and critically reviewed the manuscript. EC participated in data interpretation, statistical analysis, and drafting of the manuscript. LG conceived the study, participated in its design and coordination, interpreted the data, and drafted the manuscript. All the authors read and approved the final manuscript.

\section{Acknowledgements}

We thank Mrs. Gabriella Trudu and Mrs. Patrizia Minunno (Dipartimento di Anestesia, Rianimazione ed Emergenza Urgenza, Fondazione IRCCS Ca' Granda-Ospedale Maggiore Policlinico, Milan, Italy) for valuable logistic support. We thank Mr. Fabio Ambrosetti (Dipartimento di Fisiopatologia Medico-Chirurgica e dei Trapianti, Fondazione IRCCS Ca' Granda-Ospedale Maggiore Policlinico, Università degli Studi di Milano, Milan, Italy) for technical assistance. Funds: This study was supported in part by an Italian grant provided by the Fondazione Fiera di Milano for Translational and Competitive Research (2007, Luciano Gattinoni) and by the GE Healthcare. 


\section{Author details}

'Dipartimento di Anestesia, Rianimazione ed Emergenza Urgenza, Fondazione IRCCS Ca' Granda-Ospedale Maggiore Policlinico di Milano, Milan, Italy. ${ }^{2}$ Dipartimento di Fisiopatologia Medico-Chirurgica e dei Trapianti, Università degli Studi di Milano, Via Francesco Sforza 35, 20122 Milan, Italy. ${ }^{3}$ Centro di Ricerche Chirurgiche Precliniche, Fondazione IRCCS Ca' Granda-Ospedale Maggiore Policlinico, Università degli Studi di Milano, Milan, Italy. ${ }^{4}$ Dipartimento dei Servizi, Radiologia, Fondazione IRCCS Ca' Granda-Ospedale Maggiore Policlinico, Milan, Italy. ${ }^{5}$ Dipartimento di Elettronica, Informazione e Bioingegneria, Politecnico di Milano, Milan, Italy.

Received: 15 October 2015 Accepted: 9 December 2015

Published online: 15 December 2015

\section{References}

1. Ashbaugh DG, Bigelow DB, Petty TL, Levine BE (1967) Acute respiratory distress in adults. Lancet Lond Engl 2:319-323

2. Kumar A, Pontoppidan H, Falke KJ et al (1973) Pulmonary barotrauma during mechanical ventilation. Crit Care Med 1:181-186

3. Dreyfuss D, Soler P, Basset G, Saumon G (1988) High inflation pressure pulmonary edema. Respective effects of high airway pressure, high tidal volume, and positive end-expiratory pressure. Am Rev Respir Dis 137:1159-1164

4. Muscedere JG, Mullen JB, Gan K, Slutsky AS (1994) Tidal ventilation at low airway pressures can augment lung injury. Am J Respir Crit Care Med 149:1327-1334

5. Oeckler RA, Hubmayr RD (2008) Cell wounding and repair in ventilator injured lungs. Respir Physiol Neurobiol. doi:10.1016/j.resp.2008.06.019.

6. Ranieri VM, Suter PM, Tortorella C et al (1999) Effect of mechanical ventilation on inflammatory mediators in patients with acute respiratory distress syndrome: a randomized controlled trial. JAMA 282:54-61

7. The Acute Respiratory Distress Syndrome Network (2000) Ventilation with lower tidal volumes as compared with traditional tidal volumes for acute lung injury and the acute respiratory distress syndrome. N Engl J Med. 342:1301-1308,

8. Webb HH, Tierney DF (1974) Experimental pulmonary edema due to intermittent positive pressure ventilation with high inflation pressures. Protection by positive end-expiratory pressure. Am Rev Respir Dis 110:556-565

9. Brower RG, Lanken PN, Maclntyre N et al (2004) Higher versus lower positive end-expiratory pressures in patients with the acute respiratory distress syndrome. N Engl J Med 351:327-336

10. Meade MO, Cook DJ, Guyatt GH et al (2008) Ventilation strategy using low tidal volumes, recruitment maneuvers, and high positive end-expiratory pressure for acute lung injury and acute respiratory distress syndrome-a randomized controlled trial. Jama-J Am Med Assoc 299:637-645

11. Mercat A, Richard JCM, Vielle B et al (2008) Positive end-expiratory pressure setting in adults with acute lung injury and acute respiratory distress syndrome-a randomized controlled trial. Jama-J Am Med Assoc 299:646-655

12. Phoenix SI, Paravastu S, Columb M et al (2009) Does a higher positive end expiratory pressure decrease mortality in acute respiratory distress syndrome? A systematic review and meta-analysis. Anesthesiology 110:1098-1105

13. Briel M, Meade M, Mercat A et al (2010) Higher vs lower positive end-expiratory pressure in patients with acute lung injury and acute respiratory distress syndrome: systematic review and meta-analysis. JAMA 303:865-873

14. Protti A, Cressoni M, Santini A et al (2011) Lung stress and strain during mechanical ventilation: any safe threshold? Am J Respir Crit Care Med 183:1354-1362. doi:10.1164/rccm.201010-17570C

15. Protti A, Andreis DT, Monti M et al (2013) Lung stress and strain during mechanical ventilation: any difference between statics and dynamics? Crit Care Med 41:1046-1055. doi:10.1097/CCM.0b013e31827417a6

16. Gattinoni L, Pesenti A, Avalli L et al (1987) Pressure-volume curve of total respiratory system in acute respiratory failure. Computed tomographic scan study. Am Rev Respir Dis 136:730-736. doi:10.1164/ajrccm/136.3.730

17. Venegas JG, Harris RS, Simon BA (1998) A comprehensive equation for the pulmonary pressure-volume curve. J Appl Physiol Bethesda Md 1985 84:389-395

18. Gattinoni L, Pesenti A (1987) ARDS: the non-homogeneous lung; facts and hypothesis. Intensive Crit Care Dig 6:1-4

19. Gattinoni L, Pesenti A (2005) The concept of "baby lung.". Intensive Care Med 31:776-784

20. Chiumello D, Carlesso E, Cadringher $P$ et al (2008) Lung stress and strain during mechanical ventilation for acute respiratory distress syndrome. Am J Respir Crit Care Med 178:346-355

21. Marini JJ, Hotchkiss JR, Broccard AF (2003) Bench-to-bedside review: microvascular and airspace linkage in ventilator-induced lung injury. Crit Care Lond Engl 7:435-444. doi:10.1186/cc2392

22. Hotchkiss JR, Blanch L, Naveira A et al (2001) Relative roles of vascular and airspace pressures in ventilator-induced lung injury. Crit Care Med 29:1593-1598

23. Bshouty Z, Younes M (1992) Effect of breathing pattern and level of ventilation on pulmonary fluid filtration in dog lung. Am Rev Respir Dis 145:372-376

24. Kolobow T, Moretti MP, Fumagalli R et al (1987) Severe impairment in lung function induced by high peak airway pressure during mechanical ventilation. An experimental study. Am Rev Respir Dis 135:312-315

25. Stocks J, Quanjer PH (1995) Reference values for residual volume, functional residual capacity and total lung capacity. ATS Workshop on Lung Volume Measurements. Official statement of the European Respiratory Society. Eur Respir J 8:492-506

26. Tankersley CG, Rabold R, Mitzner W (1999) Differential lung mechanics are genetically determined in inbred murine strains. J Appl Physiol Bethesda Md 1985 86:1764-1769

27. Mitzner W, Brown R, Lee W (2001) In vivo measurement of lung volumes in mice. Physiol Genomics 4:215-221

28. Irvin CG, Bates JHT (2003) Measuring the lung function in the mouse: the challenge of size. Respir Res 4:4

29. Caironi P, Langer T, Carlesso E et al (2011) Time to generate ventilator-induced lung injury among mammals with healthy lungs: a unifying hypothesis. Intensive Care Med 37:1913-1920

30. Ibanez J, Raurich JM (1982) Normal values of functional residual capacity in the sitting and supine positions. Intensive Care Med 8:173-177 
31. Moreira LF, Aires ST, Gobbi CF et al (1995) Respiratory system, lung, and chest wall mechanics after longitudinal laparotomy in rats. Eur Respir J 8:105-108

32. Don H (1977) The mechanical properties of the respiratory system during anesthesia. Int Anesthesiol Clin 15:113-136

33. Hedenstierna G, Tokics L, Strandberg A et al (1986) Correlation of gas exchange impairment to development of atelectasis during anaesthesia and muscle paralysis. Acta Anaesthesiol Scand 30:183-191

34. Hedenstierna G, Edmark $L$ (2005) The effects of anesthesia and muscle paralysis on the respiratory system. Intensive Care Med 31:1327-1335. doi:10.1007/s00134-005-2761-7

35. Gattinoni L, Carlesso E, Cadringher P et al (2003) Physical and biological triggers of ventilator-induced lung injury and its prevention. Eur Respir J Suppl 47:15s-25s

36. Tschumperlin DJ, Oswari J, Margulies AS (2000) Deformation-induced injury of alveolar epithelial cells. Effect of frequency, duration, and amplitude. Am J Respir Crit Care Med 162:357-362. doi:10.1164/ajrccm.162.2.9807003

37. Parker JC, Breen EC, West JB (1997) High vascular and airway pressures increase interstitial protein mRNA expression in isolated rat lungs. J Appl Physiol Bethesda Md 1985 83:1697-1705

38. Al-Jamal R, Ludwig MS (2001) Changes in proteoglycans and lung tissue mechanics during excessive mechanical ventilation in rats. Am J Physiol Lung Cell Mol Physiol 281:L1078-1087

39. Pelosi P, Rocco PR (2008) Effects of mechanical ventilation on the extracellular matrix. Intensive Care Med 34:631-639. doi:10.1007/s00134-007-0964-9

40. Budinger GRS, Sznajder JI (2006) The alveolar-epithelial barrier: a target for potential therapy. Clin Chest Med 27:655-669. doi:10.1016/j.ccm.2006.06.007, abstract ix

41. West JB (1985) Invited review: pulmonary capillary stress failure. J Appl Physiol Bethesda Md 1985 89:2483-2489, discussion 2497

42. O'Neill LAJ (2005) TLRs play good cop, bad cop in the lung. Nat Med 11:1161-1162

43. Cressoni M, Cadringher $P$, Chiurazzi $C$ et al (2014) Lung inhomogeneity in patients with acute respiratory distress syndrome. Am J Respir Crit Care Med 189:149-158. doi:10.1164/rccm.201308-15670C

44. Amato MBP, Meade MO, Slutsky AS et al (2015) Driving pressure and survival in the acute respiratory distress syndrome. N Engl J Med 372:747-755. doi:10.1056/NEJMsa1410639

45. Gajic O, Dara SI, Mendez JL et al (2004) Ventilator-associated lung injury in patients without acute lung injury at the onset of mechanical ventilation. Crit Care Med 32:1817-1824

46. Serpa Neto A, Cardoso SO, Manetta JA et al (2012) Association between use of lung-protective ventilation with lower tidal volumes and clinical outcomes among patients without acute respiratory distress syndrome: a meta-analysis. JAMA 308:1651-1659. doi:10.1001/jama.2012.13730

47. Determann RM, Royakkers A, Wolthuis EK, et al. (2010) Ventilation with lower tidal volumes as compared with conventional tidal volumes for patients without acute lung injury: a preventive randomized controlled trial. Crit Care Lond Engl. doi: 10.1186/cc8230

48. Serpa Neto A, Simonis FD, Barbas CSV et al (2014) Association between tidal volume size, duration of ventilation, and sedation needs in patients without acute respiratory distress syndrome: an individual patient data meta-analysis. Intensive Care Med 40:950-957. doi:10.1007/s00134-014-3318-4

49. Severgnini $P$, Selmo G, Lanza $C$ et al (2013) Protective mechanical ventilation during general anesthesia for open abdominal surgery improves postoperative pulmonary function. Anesthesiology 118:1307-1321. doi:10.1097/ALN. Ob013e31829102de

50. Futier E, Constantin J-M, Paugam-Burtz C et al (2013) A trial of intraoperative low-tidal-volume ventilation in abdominal surgery. N Engl J Med 369:428-437. doi:10.1056/NEJMoa1301082

51. Hemmes SN, de Gama A, Pelosi P, Schultz MJ (2014) High versus low positive end-expiratory pressure during general anaesthesia for open abdominal surgery (PROVHILO trial): a multicentre randomised controlled trial. Lancet 384:495-503

52. Editorial \& Publishing Policies: Scientific Data. http://www.nature.com/sdata/for-authors/editorial-and-publishingpolicies\#prior-pub. Accessed 26 Nov 2015

Submit your manuscript to a SpringerOpen ${ }^{\circ}$ journal and benefit from:

- Convenient online submission

- Rigorous peer review

- Immediate publication on acceptance

- Open access: articles freely available online

- High visibility within the field

- Retaining the copyright to your article

Submit your next manuscript at $>$ springeropen.com 